\title{
Assessing health-related quality of life in COPD: comparing generic and disease-specific instruments with focus on comorbidities
}

Margarethe E. Wacker ${ }^{1 *}$, Rudolf A. Jörres ${ }^{2}$, Annika Karch ${ }^{3}$, Sarah Wilke ${ }^{4}$, Joachim Heinrich ${ }^{5}$, Stefan Karrasch ${ }^{2,5,6}$, Armin Koch ${ }^{3}$, Holger Schulz ${ }^{5}$, Henrik Watz ${ }^{7}$, Reiner Leidl ${ }^{1,8}$, Claus Vogelmeier ${ }^{9}$, Rolf Holle ${ }^{1}$ and for the COSYCONET-Consortium

\begin{abstract}
Background: Chronic Obstructive Pulmonary Disease (COPD) influences different aspects of patient's health-related quality of life (HRQL). While disease-specific HRQL instruments focus on symptoms and functional impairments, generic instruments cover a broader view on health. This study compares the generic EQ-5D-3 $L$ and two disease-specific questionnaires (St.-George's Respiratory Questionnaire (SGRQ-C), COPD Assessment Test (CAT)) in a comprehensive spectrum of COPD disease grades with particular attention on comorbidities and assesses the discriminative abilities of these instruments.

Methods: Using data from the baseline visit of the German COPD cohort COSYCONET, mean HRQL scores in different COPD grades were compared by linear regression models adjusting for age, sex, education, smoking status, BMI, and low vs. high number of comorbidities or a list of several self-reported comorbid conditions. Discriminative abilities of HRQL instruments to differentiate between COPD grades were assessed by standardized mean differences.

Results: In 2,291 subjects in COPD GOLD grades 1-4 EQ-5D-3 L utility, EQ-5D VAS, SGRQ, and CAT were found able to discriminate between COPD grades, with some limitations for the EQ-5D utility in mild disease. Both generic and disease-specific HRQL instruments reflected the burden of comorbid conditions. The SGRQ showed the best discrimination between COPD grades and was less influenced by comorbidities, while EQ-5D utility put a higher weight on comorbid conditions. For all instruments, psychiatric disorders and peripheral artery disease showed the strongest negative associations with HRQL.
\end{abstract}

Conclusion: All HRQL instruments considered reflect considerable impairment of HRQL in COPD patients, worsening with increasing COPD grade and number of comorbidities. Findings may support clinical assessment, choice of HRQL instrument in future studies, and parameterization of decision-analytic models.

Keywords: Chronic obstructive pulmonary disease, Health-related quality of life, Utility, Comorbidity, Cohort study, Questionnaires

\footnotetext{
* Correspondence: margarethe.wacker@helmholtz-muenchen.de

${ }^{1}$ Institute of Health Economics and Health Care Management, Helmholtz

Zentrum München GmbH - German Research Center for Environmental

Health, Comprehensive Pneumology Center Munich (CPC-M), Member of the

German Center for Lung Research (DZL), Ingolstädter Landstr. 1, 85764

Neuherberg, Germany

Full list of author information is available at the end of the article
} 


\section{Background}

Chronic Obstructive Pulmonary Disease (COPD) is a common progressive disease that is characterized by persistent airflow limitation and related to an enhanced chronic inflammatory response in the airways and the lung to noxious particles or gases [1]. Although preventable and treatable, COPD represents an important public health challenge which is projected to increase in coming years because of continued exposure to risk factors such as tobacco smoking, indoor and outdoor air pollution and the aging population. The World Health Organization predicted that COPD will become the fourth leading cause of death worldwide by 2030 [2].

Patients with COPD usually experience a decrease in their health-related quality of life (HRQL): COPD symptoms such as cough, dyspnea, and sputum production, as well as acute exacerbations of the disease, and comorbidities which are ubiquitous in COPD patients contribute to the overall severity of the disease [3-6].

HRQL as an important patient-reported outcome measure in COPD has gained attention in the last years both as an individual descriptive measure as well as an endpoint in clinical studies [7]. A large variety of generic and disease-specific HRQL instruments with proven validity and reliability is available to assess HRQL of COPD patients [8]. While disease-specific instruments focus on symptoms and functional impairments associated with COPD, generic instruments are more widely applicable irrespective of the underlying disease [7]. Therefore, they can be used to compare HRQL of diseased and healthy subjects or to compare the burden of different diseases. Some generic questionnaires are used as utility instruments e.g. for the calculation of quality-adjusted life years (QALYs) in health economic evaluations. Nevertheless, they may be less sensitive to special problems of a certain disease than disease-specific instruments.

This paper describes generic as well as disease-specific HRQL in a large cohort of patients with COPD comprising all disease grades and compares assessment properties and correlations of different HRQL instruments. HRQL instruments are analyzed regarding their ability to differentiate between COPD grades. Special attention is given to the impact of comorbid conditions in COPD patients on generic and disease-specific HRQL assuming that generic instruments are more suitable to reflect the impact of comorbidities on health status than disease-specific instruments. Furthermore, we analyze whether COPD and comorbidities have additive effects on HRQL measures and whether this is different for generic and disease-specific instruments.

\section{Methods}

\section{Patients}

This cross-sectional analysis is based on data from the baseline visit of the German national COPD cohort
COSYCONET (German COPD and Systemic Consequences - Comorbidities Network). In brief, COSYCONET recruited 2,741 patients $\geq 40$ years with physiciandiagnosed COPD by outpatient and inpatient healthcare providers, patient groups, and media campaigns and examined them in 31 study centers all over Germany between September 2010 and December 2013. Exclusion criteria were previous lung transplantation or lung volume reduction surgery and lung malignancies. All participants were clinically stable defined as no moderate or severe exacerbations for at least 4 weeks at the time of enrolment. Details on the cohort have been published elsewhere $[9,10]$.

\section{Lung function test and definition of COPD}

Standardized spirometry was performed in the COSYCONET cohort after bronchodilation with $400 \mu \mathrm{g}$ salbutamol and $80 \mu \mathrm{g}$ ipratropium bromide. COPD was defined as $\mathrm{FEV}_{1} / \mathrm{FVC}<0.7$ according to the GOLD criteria [1]. Patients were classified as grade 1 with $\mathrm{FEV}_{1} \%$ pred. $\geq$ 80 , grade 2 with $50 \leq \mathrm{FEV}_{1} \%$ pred. $<80$, grade 3 with $30 \leq \mathrm{FEV}_{1} \%$ pred. $<50$ and grade 4 with $\mathrm{FEV}_{1} \%$ pred. $<$ 30 , with predicted values based on reference equations from the Global Lung Initiative (GLI) [11]. 430 participants from the cohort reporting a physician-diagnosed COPD but with $\mathrm{FEV}_{1} / \mathrm{FVC} \geq 0.7$ were excluded from this analysis as well as 20 participants with incomplete or missing lung function data.

The BODE index [12] as established multidimensional grading system in COPD was calculated in addition based on body mass index (BMI, defined as weight in kilograms/height in squared meters), $\mathrm{FEV}_{1} \%$ pred., the 5-point modified Medical Research Council (mMRC) dyspnea scale and the six-minute walking test which was performed according to the criteria of the American Thoracic Society [13]. The BODE index ranges from 0 to 10 points with higher values indicating worse health.

\section{HRQL assessment}

HRQL was assessed by self-administered questionnaires: The St. George's Respiratory Questionnaire in its COPDspecific version (SGRQ-C) [14] and the COPD Assessment Test (CAT) were used as disease-specific HRQL instruments, and the EuroQol 5 dimensions (EQ-5D-3 L) as a generic HRQL instrument.

The SGRQ-C with 40 items provides three component scores for symptoms, activity and impact, and a total score. Each score ranges from 0 (no impairment) to 100 (worst possible). A difference of 4 unit points is considered the minimum clinically important difference (MCID) [15].

The CAT is an 8-item, short and validated tool for the assessment and monitoring of COPD [16]. Symptoms are assessed on a scale from 0 to 5 . The total score ranges from 0 to 40 with higher scores representing 
worse health status. A MCID of 2 points has been proposed [17].

The EQ-5D-3 L questionnaire is a preference-based HRQL instrument with two parts. Part 1, the descriptive section, covers five dimensions of health: mobility, selfcare, usual activities, pain/discomfort, and anxiety/depression with three levels per item (no problems, some problems, and extreme problems). An index-based utility score (EQ-5D utility) ranging from 0 to 1 can be calculated via a scoring algorithm which is based on valuations of representative general population samples. We used the German time-trade-off tariff by Greiner et al. for scoring [18]. A MCID for the utility score in COPD patients has not yet been established. Based on other diseases, it may range between 0.08-0.10 [19, 20]. Part 2, the valuation section, comprises a Visual Analog Scale (VAS) for valuing health states on a rating scale from 0 (worst imaginable health state) to 100 (best imaginable health state). A MCID of 8 points has been suggested in COPD patients with moderate to severe disease [21].

All three HRQL instruments are designed to assess current health status without specifying a recall period.

\section{Comorbidities and covariables}

Self-reported information on physician-diagnosed comorbid conditions was systematically obtained in semistructured interviews. We assessed 33 of these comorbid conditions. The number of comorbid conditions was summarized as a simple count. This approach has been shown to be a good proxy for the burden of comorbidities [22]. For defining groups with a low or a high number of comorbidities, the median number of comorbidities $(\leq 3$ vs. >3) was used as cut-off. A list of all comorbidities considered can be found in the (Additional file 1: Figure S1).

Information on age, sex, school education (basic ( $\leq 9$ years), secondary (10-11 years), higher ( $\geq 12$ years)), and smoking status (current, former, and never smoker) was collected by standardized questionnaires. BMI was measured at the study centers and classified as normal weight $(18.5 \leq \mathrm{BMI}<25)$, overweight $(25 \leq \mathrm{BMI}<30)$, obese $(\mathrm{BMI} \geq 30)$, and underweight $(\mathrm{BMI}<18.5)$.

\section{Statistical analysis}

Characteristics of COPD patients in different grades were compared using analysis of variance (ANOVA) for continuous variables and $\mathrm{Chi}^{2}$-tests for categorical variables. For each HRQL instrument, the proportion of participants with the worst or best possible health state was determined to assess the presence of floor or ceiling effects. Bivariate correlations between the HRQL instruments and with clinical COPD measures were quantified by Spearman's rank coefficient.
To assess the association of COPD grades 1-4 with HRQL and the discriminative ability of HRQL instruments, linear regression models were performed adjusting for age, sex, education, smoking status, BMI, and low vs. high number of comorbidities. The number of comorbid conditions as a continuous variable was considered in a sensitivity analysis instead of the dichotomized variable. Adjusted mean HRQL scores resulting from the regression models were reported for COPD grade 1-4 as well as for the group with a low or high number of comorbidities. Standardized mean differences were calculated as the mean adjusted difference between two COPD grades divided by their pooled (unadjusted) standard deviation (SD) [23] in order to assess the magnitude of the difference and to judge the ability of HRQL instruments for discrimination. In additional models, non-additive effects of COPD and comorbidity were checked by interaction terms between COPD grades and low or high number of comorbidities. Pseudo- $\mathrm{R}^{2}$ according to Cox \& Snell [24] were calculated to compare the additional variance explained by COPD grade and/or low vs. high number of comorbidities in models for all HRQL instruments.

Further models were calculated controlling for all single comorbidities instead of a comorbidity count to identify the most important comorbid conditions for each HRQL instrument, again adjusted for age, sex, education, smoking status, and BMI.

Statistical analyses were performed using SAS software (SAS Institute Inc., Cary, NC, USA, version 9.3), and $p$ values of 0.05 or less were considered to be statistically significant.

\section{Results}

The characteristics of the 2,291 COPD patients in grade 1 to 4 included for analysis are shown in Table 1 . The majority of patients was male with a mean age of 65 years, $\mathrm{FEV}_{1}$ of $52.5 \%$ predicted, BODE index of 2.5 , and 3.7 selfreported comorbidities. Most of the COPD patients were in GOLD grade 2 (42\%) and 3 (38\%). COPD grades were comparable in their gender distribution while they differed significantly regarding age, education, smoking status, BMI, and the number of comorbidities.

\section{Completeness of HRQL questionnaires, floor- and ceiling effects and correlations}

Completeness of questions was $>98.8 \%$ in all HRQL instruments. COPD-specific HRQL instruments and EQ$5 \mathrm{D}$ VAS showed no floor or ceiling effects. Regarding the EQ-5D descriptive section, $18 \%$ of patients reported the best health state (11111).

With regard to the relationship between the HRQL instruments, correlations between EQ-5D utility index and disease-specific HRQL scores were moderate $(r h o=-0.56$ 
Table 1 Characteristics of the study population and unadjusted means of HRQL

\begin{tabular}{|c|c|c|c|c|c|c|c|}
\hline & & Total sample & COPD grade 1 & COPD grade 2 & COPD grade 3 & COPD grade 4 & $p$-value \\
\hline \multicolumn{2}{|l|}{ n (\%) } & 2,291 & $206(9.0)$ & $962(42.0)$ & $874(38.1)$ & $249(10.9)$ & \\
\hline \multirow[t]{5}{*}{ Age } & Mean age (SD) & $65.1(8.4)$ & $66.2(8.7)$ & $65.7(8.5)$ & $65.0(8.2)$ & $62.1(8.0)$ & $<0.0001$ \\
\hline & $\%<55$ years $(n)$ & $11.4(262)$ & $9.7(20)$ & $10.3(99)$ & $11.2(98)$ & $18.1(45)$ & \multirow[t]{4}{*}{$<0.0001$} \\
\hline & $\% 55-64$ years $(n)$ & $33.6(769)$ & $27.2(56)$ & $31.7(305)$ & $34.3(300)$ & $43.4(108)$ & \\
\hline & $\% 65$ - 74 years $(n)$ & $43.2(989)$ & $48.1(99)$ & $44.5(428)$ & $43.8(383)$ & 31.7 (79) & \\
\hline & $\%>74$ years $(n)$ & $11.8(271)$ & $15.1(31)$ & $13.5(130)$ & $10.6(93)$ & $6.8(17)$ & \\
\hline Sex & $\%$ male $(n)$ & $60.9(1,396)$ & $60.2(124)$ & $60.2(579)$ & $61.0(533)$ & $64.3(160)$ & 0.70 \\
\hline \multirow[t]{3}{*}{ School education } & \% basic education (n) & $55.4(1,270)$ & $48.5(100)$ & $52.2(502)$ & $60.0(524)$ & $57.8(144)$ & \multirow[t]{3}{*}{0.0002} \\
\hline & $\%$ secondary education ( $\mathrm{n}$ ) & $27.1(620)$ & $25.2(52)$ & $28.6(275)$ & $25.2(220)$ & $29.3(73)$ & \\
\hline & $\%$ higher education (n) & $17.5(401)$ & $26.2(54)$ & $19.2(185)$ & $14.9(130)$ & $12.9(32)$ & \\
\hline \multirow[t]{3}{*}{ Smoking status } & $\%$ smokers (n) & $24.7(565)$ & $30.1(62)$ & $28.8(277)$ & $21.7(190)$ & $14.5(36)$ & \multirow[t]{3}{*}{$<0.0001$} \\
\hline & $\%$ former smokers (n) & $68.8(1,576)$ & $62.6(129)$ & $63.6(612)$ & $72.7(635)$ & $80.3(200)$ & \\
\hline & $\%$ never smokers (n) & $6.6(150)$ & $7.3(15)$ & $7.6(73)$ & $5.6(49)$ & $5.2(13)$ & \\
\hline \multirow[t]{5}{*}{ BMI } & Mean BMI (SD) ${ }^{a}$ & $26.7(5.2)$ & $26.6(4.6)$ & $27.4(5.1)$ & $26.4(5.4)$ & $24.4(5.0)$ & $<0.0001$ \\
\hline & \% normal weight (n) & $37.1(848)$ & $36.4(75)$ & $32.6(313)$ & $38.5(336)$ & $49.8(124)$ & \multirow[t]{4}{*}{$<0.0001$} \\
\hline & $\%$ overweight (n) & $37.1(848)$ & $42.2(87)$ & $38.9(374)$ & $36.2(316)$ & $28.5(71)$ & \\
\hline & $\%$ obese $(n)$ & $22.4(512)$ & $19.9(41)$ & $27.0(259)$ & $20.9(182)$ & $12.1(30)$ & \\
\hline & \% underweight (n) & $3.5(81)$ & $1.5(3)$ & $1.6(15)$ & $4.5(39)$ & $9.6(24)$ & \\
\hline \multicolumn{2}{|l|}{ Mean $\mathrm{FEV}_{1} \%$ pred. } & $52.5(18.6)$ & $88.6(8.1)$ & $62.7(8.3)$ & $40.7(5.6)$ & $24.8(3.9)$ & $<0.0001$ \\
\hline \multicolumn{2}{|c|}{ Mean BODE index (SD) ${ }^{b}$} & $2.5(2.0)$ & $0.4(0.7)$ & $1.3(1.2)$ & $3.6(1.5)$ & $5.3(1.6)$ & $<0.0001$ \\
\hline \multirow[t]{3}{*}{ Comorbidities } & Mean number (SD) & $3.7(2.6)$ & $4.1(2.7)$ & $3.9(2.6)$ & $3.7(2.6)$ & $3.1(2.3)$ & $<0.0001$ \\
\hline & $\%$ low number of comorbidities ( $n$ ) & $52.6(1,206)$ & $48.5(100)$ & $50.6(487)$ & $52.9(462)$ & $63.1(157)$ & \multirow[t]{2}{*}{0.003} \\
\hline & $\%$ high number of comorbidities ( $n$ ) & $47.4(1,085)$ & $51.5(106)$ & $49.4(475)$ & $47.1(412)$ & $37.0(92)$ & \\
\hline \multirow[t]{4}{*}{ HRQL } & EQ-5D utility (SD) ${ }^{c}$ & $0.82(0.20)$ & $0.85(0.18)$ & $0.84(0.19)$ & $0.81(0.21)$ & $0.74(0.24)$ & $<0.0001$ \\
\hline & EQ-5D VAS (SD) ${ }^{d}$ & $56.5(19.6)$ & $66.9(17.4)$ & $61.0(18.8)$ & $52.2(18.8)$ & $45.5(17.8)$ & $<0.0001$ \\
\hline & CAT score (SD) e & $18.2(7.4)$ & $14.2(6.8)$ & $16.9(7.1)$ & $19.4(7.2)$ & $22.1(6.8)$ & $<0.0001$ \\
\hline & SGRQ score $(S D)^{f}$ & $43.6(20.0)$ & $28.0(15.8)$ & $38.7(19.1)$ & $48.6(17.9)$ & $58.4(18.0)$ & $<0.0001$ \\
\hline
\end{tabular}

${ }^{a} n=2,289,{ }^{b} n=2,197,{ }^{c} n=2,277,{ }^{d} n=2,266,{ }^{e} n=2,276,{ }^{f} n=2,272$

for both CAT and SGRQ). Compared to the EQ-5D utility score, the VAS showed a stronger correlation with the CAT score $(r h o=-0.62)$ and the SGRQ total score $(\mathrm{rho}=-0.65)$. Regarding the correlations of HRQL instruments with measures of disease severity, the highest correlation was found between the SGRQ total or activity score and the BODE index (rho $=0.61$ or rho $=0.67$ ). COPD grade correlated best with the SGRQ total score $($ rho $=0.40)$ and activity score $(r h o=0.46)$. The BODE index correlated better with HRQL instruments than GOLD grade. For the number of comorbid conditions, correlation was best for EQ-5D utility (rho $=-0.29)$.

An overview of correlations can be found in Additional file 1: Table S1.

\section{HRQL scores in different COPD grades}

In an unadjusted comparison, higher COPD grades showed gradually worse generic and disease-specific HRQL scores
(Table 1). Individual variability within the COPD grades was high (Additional file 1: Figure S2).

Table 2 shows the association of COPD grades with HRQL measures after adjusting for possible confounders. Patients in COPD grades $2-4$ had significantly worse HRQL across all instruments and scales compared to COPD grade 1, except for the EQ-5D utility. For example, COPD grade 2 was associated with a 5.7 point reduction of the ED-5D VAS $(p<0.0001)$. This reduction increased to 22.1 points for COPD grade $4(p<0.0001)$.

Adjusted mean HRQL scores by COPD grade are illustrated in Fig. 1. There were clear graduations between COPD grades in all instruments except for the EQ-5D utility in grade 1 and 2. Especially, the SGRQ score seemed to increase linearly with disease grade. When considering the number of comorbid conditions as a continuous instead of a dichotomized variable, the adjusted means per COPD grade were virtually unchanged. 
Table 2 Results of regression analyses

\begin{tabular}{|c|c|c|c|c|c|c|c|c|c|}
\hline & & EQ-5D uti & & EQ-5D VA & & CAT score & & SGRQ tota & ore \\
\hline & & Estimate & $p$-value & Estimate & $p$-value & Estimate & $p$-value & Estimate & $p$-value \\
\hline COPD & Grade 4 & -0.13 & $<0.0001$ & -22.11 & $<0.0001$ & 7.92 & $<0.0001$ & 31.71 & $<0.0001$ \\
\hline & Grade 3 & -0.04 & 0.005 & -14.61 & $<0.0001$ & 4.98 & $<0.0001$ & 20.41 & $<0.0001$ \\
\hline & Grade 2 & -0.006 & 0.69 & -5.67 & $<0.0001$ & 2.47 & $<0.0001$ & 10.28 & $<0.0001$ \\
\hline & Grade 1 & ref. & & ref. & & ref. & & ref. & \\
\hline Comorbidities & High number & -0.09 & $<0.0001$ & -5.75 & $<0.0001$ & 2.91 & $<0.0001$ & 7.90 & $<0.0001$ \\
\hline & Low number & ref. & & ref. & & ref. & & ref. & \\
\hline Age & $>74$ years & -0.01 & 0.59 & -1.44 & 0.38 & -2.05 & 0.001 & 1.20 & 0.45 \\
\hline & $65-74$ years & 0.01 & 0.36 & 1.04 & 0.43 & -1.55 & 0.002 & 0.23 & 0.86 \\
\hline & $55-64$ years & -0.001 & 0.97 & 0.26 & 0.84 & -0.60 & 0.23 & 0.26 & 0.84 \\
\hline & $<55$ years & ref. & & ref. & & ref. & & ref. & \\
\hline Sex & Female & -0.02 & 0.06 & 1.53 & 0.06 & 0.16 & 0.60 & 0.90 & 0.25 \\
\hline & Male & ref. & & ref. & & ref. & & ref. & \\
\hline School education & Higher & 0.05 & $<0.0001$ & 3.08 & 0.003 & -1.77 & $<0.0001$ & -4.58 & $<0.0001$ \\
\hline & Secondary & 0.02 & 0.06 & 3.10 & 0.001 & -0.88 & 0.01 & -3.26 & 0.0002 \\
\hline & Basic & ref. & & ref. & & ref. & & ref. & \\
\hline Smoking status & Current smoker & -0.01 & 0.46 & -0.13 & 0.94 & 0.74 & 0.25 & 1.19 & 0.47 \\
\hline & Former smoker & -0.02 & 0.29 & 0.29 & 0.85 & 0.18 & 0.77 & 1.45 & 0.34 \\
\hline & Never smoker & ref. & & ref. & & ref. & & ref. & \\
\hline BMI & Overweight & -0.03 & 0.007 & -1.53 & 0.09 & 0.14 & 0.68 & 1.50 & 0.08 \\
\hline & Obese & -0.06 & $<0.0001$ & -4.68 & $<0.0001$ & 1.64 & $<0.0001$ & 6.40 & $<0.0001$ \\
\hline & Underweight & 0.002 & 0.93 & -5.59 & 0.01 & 0.87 & 0.28 & 1.97 & 0.34 \\
\hline & Normal weight & ref. & & ref. & & ref. & & ref. & \\
\hline
\end{tabular}

Figure 2 shows the calculated effect sizes to assess the importance of the differences between COPD grades. The SGRQ total score showed the best discrimination between all grades of COPD. The CAT score and the VAS could also equally differentiate between COPD grades both in early and advanced disease grades, whereas the EQ-5D utility differentiated much better between COPD patients in grade 3 and 4 than in earlier grades.

\section{HRQL instruments and comorbid conditions}

Having 4 or more comorbidities was significantly associated with worse HRQL in all instruments, as shown in Table 2. As to EQ-5D VAS and CAT, the effect estimate of a high number of comorbidities compared to a low number of comorbidities was approximately of the same size than the difference between COPD grade 1 and 2 . For the SGRQ, the comorbidity estimate was lower than the estimate of COPD grade 2, but still higher than the suggested MCID. Compared to the estimates of the COPD grades, the effect estimate of high comorbidity was highest as to the EQ-5D utility, ranking between grade 3 and 4. Adjusted mean HRQL scores by comorbidity group are illustrated in Fig. 1. Combining with disease severity, adjusted mean HRQL scores for comorbidity- group by COPD grade are reported in the Additional file 1: Table S2.

In additional models including interaction terms, the effects of COPD grades and comorbidity on HRQL measures were found to be additive, as all interaction terms were non-significant (estimates shown in Additional file 1: Table S3).

When controlling for COPD grades in addition to age, sex, education, smoking status and BMI in regression models, the increase of explained variance was higher for the VAS, CAT, and SGRQ score than for the EQ-5D utility. In contrast, controlling for a low vs. high number of comorbidities resulted in a higher percentage of explained variance for the EQ-5D utility than for VAS, CAT, and SGRQ. Details on the values of $R^{2}$ are shown in Table 3.

When considering single comorbidities instead of a comorbidity count, psychological disorders comprising depression and anxiety showed one of the highest effect estimates in all models, both for generic and diseasespecific instruments (Table 4). Furthermore, peripheral artery disease (PAD) ranked among the top 5 of comorbidities with negative effects on HRQL in all models as well as sleep apnea except for the EQ-5D utility. Obesity 


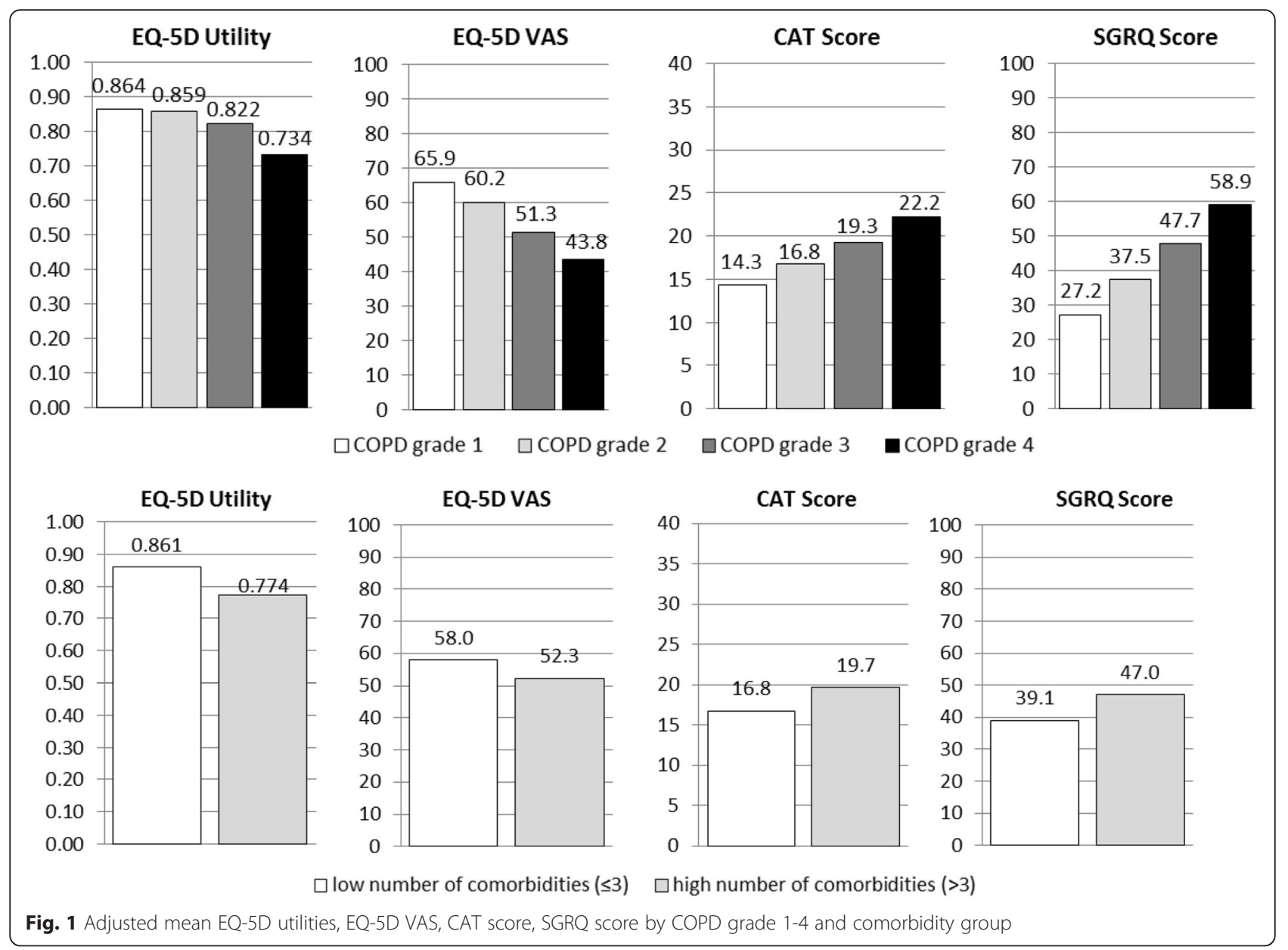

was also significantly associated with a considerably reduced HRQL in all instruments.

For the disease-specific instruments as well as the VAS, the effect estimates of all single comorbid conditions were comparable to or smaller than the estimate of COPD grade 2 (Table 4). For the EQ-5D utility, all estimates of the 5 comorbidities with the largest effects ranged between the effect of COPD grade $3(-0.05)$ and grade $4(-0.14)$.

\section{Discussion}

This study performed a comparison of the most frequently used generic and disease-specific HRQL instruments in a large cohort of COPD patients in all levels of airflow limitation with particular attention on the association with a comprehensive list of comorbid conditions.

Our study confirms that mean scores of SGRQ, CAT, EQ-5D utility, and EQ-5D VAS worsen with increasing COPD grade, despite high variability within each grade. EQ-5D utility and VAS as generic HRQL instruments and SGRQ and CAT as disease-specific instruments were found able to discriminate between COPD grades, with some limitations for the EQ-5D utility in mild COPD.
Utility results which are based on population preferences and therefore introduce external HRQL valuation put the highest weight on comorbid conditions. However, disease-specific HRQL instruments also reflected the burden of comorbid conditions. Non-additive effects of COPD and comorbidity were not observed. When focusing on single comorbid conditions, psychiatric disorders and peripheral artery disease ranked among the top 5 comorbid conditions with negative associations with HRQL for all instruments. Sleep apnoea, brain deficiency, asthma, and heart disease were also important contributors to low HRQL.

Regarding mean HRQL scores per COPD grade or correlation of disease-specific and generic HRQL measures, our results are in line with previous studies. Despite the differences in underlying populations, the mean CAT scores of our study fit very well in the range of means reported in a systematic review on studies using the CAT by Gupta et al. [25]. In a small sample of US veterans in COPD grades $1-4(n=120)$, Pickard et al. reported correlations between EQ-5D utility or VAS and SGRQ total score similar to our findings [26]. The EQ-5D VAS means, which were considerably higher than in our study, differed 
COPD grade 1 vs. grade 2

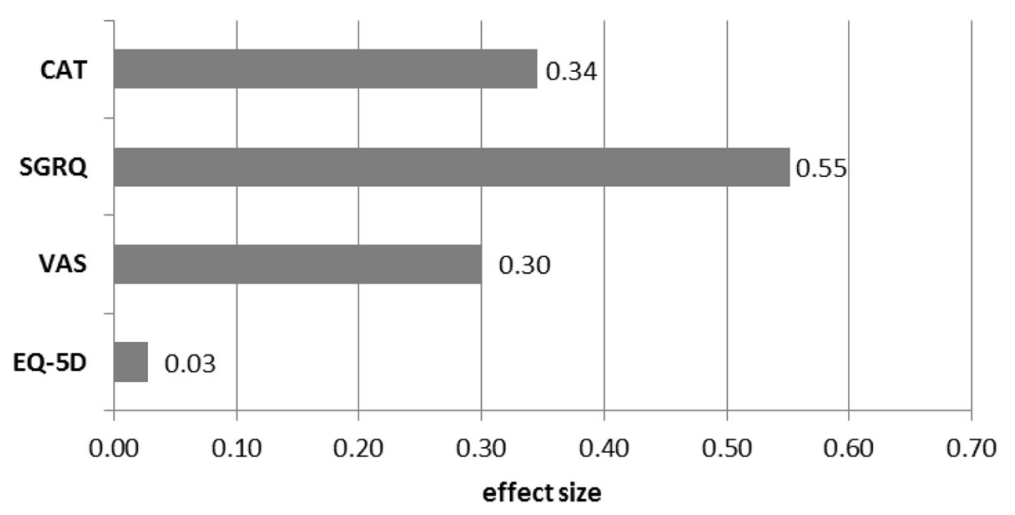

COPD grade 2 vs. grade 3

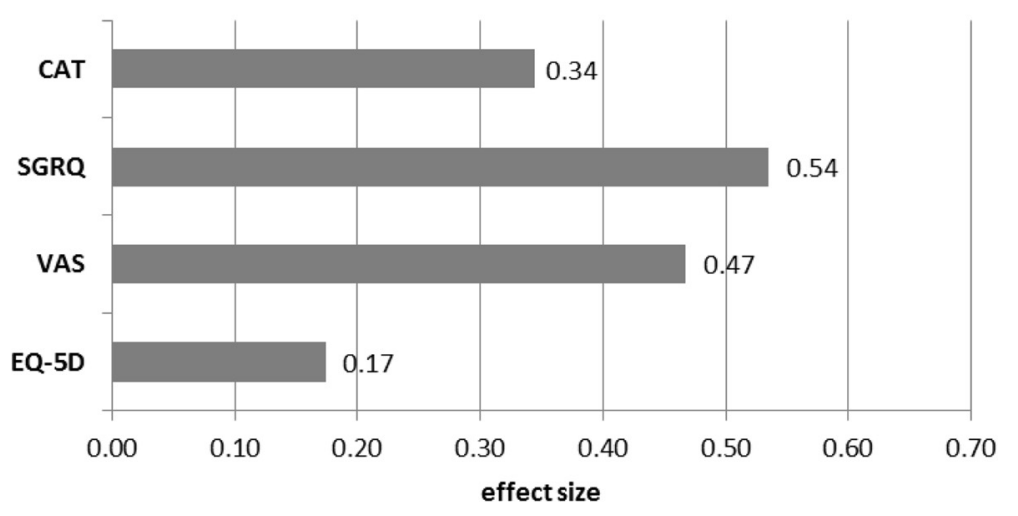

COPD grade 3 vs. grade 4

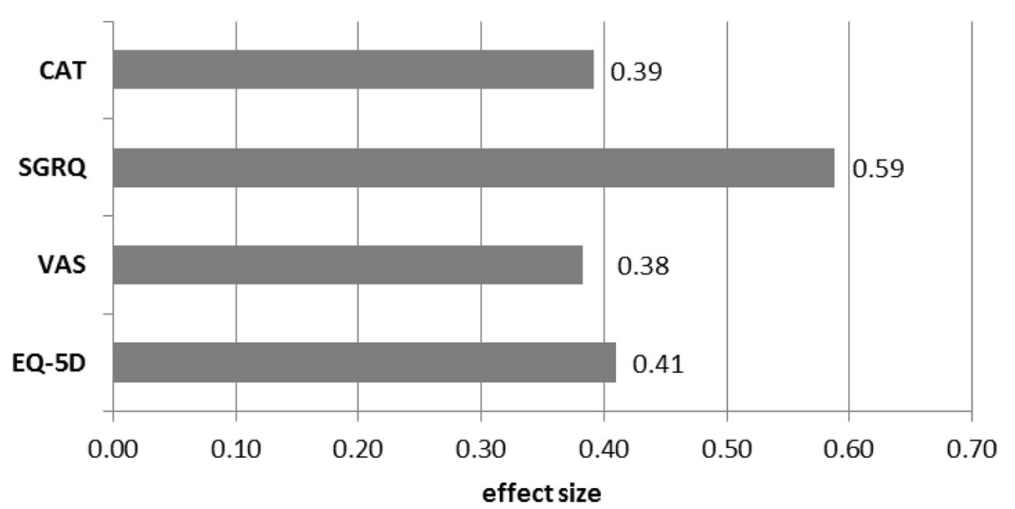

Fig. 2 Standardized absolute mean differences between COPD grades

Table 3 Comparison of pseudo-R-squared ${ }^{\mathrm{a}}$ of different models (percentage of variance explained by different models)

\begin{tabular}{|c|c|c|c|c|}
\hline Models considering... & EQ-5D utility & EQ-5D VAS & CAT score & SGRQ total score \\
\hline Age, sex, education, smoking status, BMI category & 0.034 & 0.029 & 0.041 & 0.043 \\
\hline Age, sex, education, smoking status, BMI category and COPD grade & 0.063 & 0.125 & 0.112 & 0.201 \\
\hline $\begin{array}{l}\text { Age, sex, education, smoking status, BMl category and low/high } \\
\text { number of comorbidities }\end{array}$ & 0.074 & 0.048 & 0.074 & 0.075 \\
\hline $\begin{array}{l}\text { Age, sex, education, smoking status, BMI category, COPD grade } \\
\text { and low/high number of comorbidities }\end{array}$ & 0.106 & 0.145 & 0.149 & 0.238 \\
\hline
\end{tabular}

${ }^{\mathrm{a}} \mathrm{R}^{2}$ according to Cox \& Snell [24] 
Table 4 Effect estimates of top 5 single comorbid conditions with significant negative association with HRQL scores

\begin{tabular}{|c|c|c|c|c|c|c|c|c|c|c|c|c|}
\hline Rank & EQ-5D utilit & & & EQ-5D VAS & & & CAT & & & SGRQ & & \\
\hline 1 & $\begin{array}{l}\text { Psychiatric } \\
\text { disorder }{ }^{a}\end{array}$ & -0.09 & $(p<0.0001)$ & $\begin{array}{l}\text { Brain } \\
\text { deficiency } b\end{array}$ & -5.9 & $(p=0.001)$ & $\begin{array}{l}\text { Psychiatric } \\
\text { disorder }^{a}\end{array}$ & 2.5 & $(p<0.0001)$ & $\begin{array}{l}\text { Psychiatric } \\
\text { disorder }^{a}\end{array}$ & 7.2 & $(p<0.0001)$ \\
\hline 2 & Arthritis & -0.06 & $(p<0.0001)$ & $\begin{array}{l}\text { Psychiatric } \\
\text { disorder }^{a}\end{array}$ & -5.3 & $(p<0.0001)$ & Asthma & 1.7 & $(p<0.0001)$ & PAD & 5.0 & $(p<0.0001)$ \\
\hline 3 & PAD & -0.05 & $(p<0.0001)$ & PAD & -3.4 & $(p=0.005)$ & Sleep apnea & 1.5 & $(p=0.002)$ & Brain deficiency & 4.6 & $(p=0.005)$ \\
\hline 4 & Arthrosis & -0.05 & $(p=0.0003)$ & Asthma & -3.4 & $(p=0.001)$ & Heart disease ${ }^{c}$ & 1.5 & $(p<0.0001)$ & Sleep apnea & 4.3 & $(p=0.0004)$ \\
\hline 5 & Migraine & -0.05 & $(p<0.0001)$ & Sleep apnea & -2.8 & $(p=0.03)$ & PAD & 1.4 & $(p=0.002)$ & Heart disease ${ }^{c}$ & 4.1 & $(p<0.0001)$ \\
\hline
\end{tabular}

all models adjusted for age, sex, school education, smoking status, BMI category, and GOLD grade

${ }^{a}$ comprising anxiety, depression, psychoses

${ }^{\mathrm{b}}$ comprising weakness of memory, disorientation, confusion

comprising cardiac arrhythmia, cardiac insufficiency, narrow coronary vessel, angina pectoris

between COPD grades 1-4, while EQ-5D utilities did not. In line with our results, best discriminative properties between COPD grades were reported for the SGRQ in this study.

Our results showed clear HRQL differences between COPD grade 1 and 2 (except for EQ-5D utility), while some previous studies did not observe HRQL differences between milder COPD grades. E.g., Jones et al. did not find differences in SGRQ total score and the generic SF12 questionnaire between primary care COPD patients in grade 1 and 2 . This might be due to the fact that reported SGRQ means for grade 1 were more than 10 points higher than in our sample, while mean values for grades 2,3 and 4 as reported in Jones et al. were comparable to our results [27]. In the same population, Jones et al. did not find significant differences in CAT scores between COPD grade 1 and 2 [28]. A possible explanation for this lack of differences between these grade 1 and 2 patients may be that symptoms and HRQL impairment are important drivers for the patients to see their primary care physician.

For health-economic evaluations in COPD, it is important to know the discriminative abilities of the EQ-5D questionnaire because it is frequently applied for determining utilities needed for the calculations of quality-adjusted life years (QALYs) [29]. Based on data from UPLIFT, a large COPD trial covering 13 countries, Rutten-van Mölken et al. investigated discriminative abilities of the EQ-5D questionnaire in COPD patients [29]. This study found better discriminative properties of the EQ-5D utility in higher COPD grades, but did not include COPD grade 1. When comparing EQ-5D utilities, it has to be kept in mind that utilities depend on the underlying country-specific tariff and methods (time trade off vs. standard gamble) used for their calculation. Furthermore, ceiling effects may limit the sensitivity of the utility.

There seems to be a consensus that COPD patients with a higher number of comorbid conditions have a worse HRQL [27, 28, 30-34]. Several previous studies supplied evidence that comorbidities in patients with
COPD are associated with worse COPD-specific HRQL scores [6, 27, 28, 31, 35, 36]. In a hospital-based COPD cohort, Koskela et al. also found that a generic HRQL instrument better captured the effects of comorbid conditions but that these conditions were also associated with COPD-specific HRQL [3]. For COPD patients with three or more comorbid conditions, Jones et al. reported significantly worse CAT (+2.5 units) [28] and SGRQ scores (approx. +8 units) [27] than for patients without or with 1-2 comorbidities. Despite referring to different comorbid conditions, these extra units correspond well to the estimates of high comorbidity found in our study.

When focusing on single comorbid conditions, especially mental health problems are often reported contributors to decreased HRQL in COPD [3, 5, 6, 31, 34, 37]. This was confirmed by our analysis. In general, a direct comparison of the effects of single comorbidities on HRQL in COPD patients is often hampered by different conditions considered and diverging definitions. Depression, anxiety, and PAD which we identified as the most important comorbidities in our study, were also included in the recently published COMCOLD index that identified five comorbidities with the highest effect on the VAS [38]. Further comparison with the two additional comorbidities of this index (symptomatic heart disease and cerebrovascular disease) was not possible due to differences in definitions.

Urff et al. reported that COPD patients with depression or heart failure had considerably lower disease-specific HRQL as measured by the Clinical COPD Questionnaire (CCQ) [36] and explained this finding by overlapping symptoms of COPD and depression or heart failure. Having the items of EQ-5D, CAT, and SGRQ in mind, another reason could be that there is an overlap of these instruments with regard to psychological and mobility aspects of health. Therefore, it is not surprising that especially psychological disorders and PAD showed the strongest associations with the HRQL scores in our analysis. We did not consider dyspnea and exacerbation frequency in our multivariate analysis. As the CAT and SGRQ include dyspnea and symptoms of exacerbations already in their 
items, controlling for these factors as explanatory variables would cause problems of circularity. The finding that the multidimensional BODE index showed higher correlation with HRQL scores than COPD grades is in line with this reasoning because BODE includes $\mathrm{mMRC}$ as a measure of dyspnea and the 6-minute-walking-test as a measure of physical capacity.

Further explanations for the ability of disease-specific HRQL instruments to reflect the burden of comorbidity need to be addressed in future research.

Several strengths of our study have to be considered. Based on a large patient sample comprising all COPD grades, our analysis had sufficient power to detect differences between grades. A comprehensive list of comorbid conditions was available and possible interactions between COPD and comorbidity were analyzed. Therefore, the results of our observational study might be more generalizable than results from clinical trials where patients with comorbidities are often excluded.

There are, however, also potential limitations: First, since only cross-sectional data were available, we were not able to investigate the responsiveness of HRQL instruments or sensitivity to change over time. Second, data on physician-diagnosed comorbidities were self-reported which might limit their validity, and no information on the severity of comorbid conditions was available. Furthermore, comorbid conditions were summarized and dichotomized without weighting. However, this approach has been shown to perform just as well as weighted scores to quantify the impact of comorbidities on disease-specific HRQL in COPD patients [22].

Nevertheless, from a research perspective, our direct comparison of HRQL instruments did not show a clear ranking. The decision for a generic or disease-specific instrument must be based on the purpose of HRQL measurement. Cross-sectional comparisons of COPD patients (with or without control subjects) or a longitudinal monitoring of disease progression pose different demands on HRQL instruments. Researchers are responsible to ensure that the chosen HRQL instrument addresses the problems of the research questions. While generic instruments allow comparisons of groups with different conditions, may support the identification of unexpected HRQL issues, and are need for the calculation of QALYs in economic evaluations, disease-specific instruments are more likely to detect small, but relevant changes [39]. Furthermore, by focusing on relevant dimensions of the disease, diseasespecific instruments may have a higher acceptability among patients and thus increased responsiveness.

However, we have shown that the effect of comorbid conditions on HRQL was both apparent in generic and to a smaller degree in COPD-specific HRQL measures. This finding is consistent with studies from other diseases [40]. To cover all aspects of HRQL in COPD, both generic and disease-specific instruments should be used in the ideal case. With regard to economic evaluations, further research is needed towards the discriminative properties of the new EQ-5D 5-level version in COPD.

From a clinical perspective, our results underline the need for a holistic approach for COPD healthcare with a mandatory screening for comorbidities, assessment of $\mathrm{HRQL}$ and in consequence a multidisciplinary treatment as generic and also COPD-specific health status could be improved [41].

\section{Conclusion}

This large observational study confirms that HRQL is considerably impaired in COPD patients and worsens with disease deterioration and higher comorbidity. Findings underline the need of diagnosing and treating comorbid conditions in COPD patients as generic and also COPD-specific health status could be improved. Results may further be useful for choosing HRQL instruments in future clinical studies, and for parameterizing decisionanalytic COPD models.

\section{Ethics approval and consent to participate}

The COSYCONET study complies with the Declaration of Helsinki and Good Clinical Practice Guidelines and has been approved by the ethics committee of the medical faculty of the Philipps-Universität Marburg, the local ethics committees of the participating centers (a list of all participating study centers can be found here: http:// www.asconet.net/html/cosyconet/studzent) and by the concerned data security authority (data security agency of the federal states of Hesse, Baden-Württemberg, Lower-Saxony, and Saarland). All participants provided written informed consent.

\section{Availability of data and materials}

The full dataset supporting the conclusions of this article is available upon request and application from the Competence Network Asthma and COPD (ASCONET, http://www.asconet.net/html/cosyconet/projects).

\section{Consent for publication}

Not applicable.

\section{Additional file}

Additional file 1: Table S1. Correlations between $H R Q L$ instruments and with GOLD grade and BODE as clinical measures: Spearman Correlation Coefficients. Table S2. Adjusted mean EQ-5D utilities, EQ-5D VAS, CAT score, SGRQ total scores for COPD grade 1-4 stratified for group with low $(\leq 3)$ or high (>3) number of comorbidities. Table S3. Results of regression models considering interactions between COPD grades and low/high number of comorbidity. Figure S1. Lifetime prevalence of self-reported comorbidities (\%) in the study population. Figure S2. HRQL scores by FEV1 \% pred.: nonparametric quantile regression: quantile fit plots for $\mathrm{FEV}_{1} \%$ pred. (DOC 258 kb) 


\section{Abbreviations}

ANOVA: analysis of variance; BMI: body mass index; BODE: body-mass index, aifflow obstruction, dyspnea and exercise capacity index; CAT: COPD assessment test; COPD: chronic obstructive pulmonary disease; COSYCONET: German COPD and Systemic Consequences - Comorbidities Network; EQ-5D-3 L: EuroQol 5 dimensions questionnaire with 3 levels; $\mathrm{FEV}_{1}$ : forced expiratory volume in 1 second; FVC: forced vital capacity; HRQL: health-related quality of life; MCID: minimum clinically important difference; PAD: peripheral artery disease; QALY: quality-adjusted life year; SD: standard deviation; SGRQ-C: St. George's Respiratory Questionnaire, COPD-specific version; VAS: visual analog scale.

\section{Competing interests}

CV reports personal fees from Almirall, AstraZeneca, Boehringer Ingelheim, Chiesi, GlaxoSmithKline, Grifols, Janssen, Mundipharma, Novartis, Takeda, and Cipla outside the submitted work. All other authors have no relevant conflicts of interest.

\section{Authors' contributions}

MW and RH conceptualized the paper. MW, AKa, RH performed the statistical analysis and interpreted the data. MW, RH drafted the manuscript. RJ, HS, SK, $J H, A K o, H W, R L, C V$ were involved in the coordination of the study and all commented on drafts of the paper. All authors critically reviewed each draft of the manuscript and approved the final manuscript.

\section{Authors' information}

Not applicable.

\section{Acknowledgements}

Not applicable.

\section{Funding}

This work was supported by the Competence Network Asthma and COPD (ASCONET). The COSYCONET COPD Cohort is funded by the German Federal Ministry of Education and Research (BMBF) with grant numbers 01GI0881, 01G10882 and by unrestricted grants from several pharmaceutical companies.

\section{Author details}

${ }^{1}$ Institute of Health Economics and Health Care Management, Helmholtz Zentrum München GmbH - German Research Center for Environmental Health, Comprehensive Pneumology Center Munich (CPC-M), Member of the German Center for Lung Research (DZL), Ingolstädter Landstr. 1, 85764 Neuherberg, Germany. ${ }^{2}$ Institute and Outpatient Clinic for Occupational, Social and Environmental Medicine, Ludwig-Maximilians-Universität München, Ziemssenstr. 1, 80336 Munich, Germany. ${ }^{3}$ Institute for Biostatistics, Hannover Medical School, Carl-Neuberg-Str. 1, 30625 Hannover, Germany. ${ }^{4}$ Department of Research \& Education, CIRO, Hornerheide 1, 6085, NM, Horn, The Netherlands. ${ }^{5}$ Institute of Epidemiology I, Helmholtz Zentrum München $\mathrm{GmbH}$ - German Research Center for Environmental Health, Comprehensive Pneumology Center Munich (CPC-M), Member of the German Center for Lung Research (DZL), Ingolstädter Landstr. 1, 85764 Neuherberg, Germany. ${ }^{6}$ Institute of General Practice, University Hospital Klinikum rechts der Isar, Technische Universität München, Orleansstr. 47, 81667 Munich, Germany. ${ }^{7}$ Pulmonary Research Institute at LungenClinic Grosshansdorf, Airway Research Center North (ARCN), Member of the German Center for Lung Research (DZL), Wöhrendamm 80, 22927 Grosshansdorf, Germany. ${ }^{8}$ Institute of Health Economics and Health Care Management, Munich Center of Health Sciences, Ludwig-Maximilians-Universität München, Ludwigstr. 28/RG, 80539 Munich, Germany. ${ }^{9}$ Department of Respiratory Medicine, University of Marburg, University Giessen and Marburg Lung Center (UGMLC), Member of the German Center for Lung Research (DZL), Baldingerstraße, 35043 Marburg, Germany.

\section{Received: 25 February 2016 Accepted: 1 May 2016}

\section{Published online: 10 May 2016}

\section{References}

1. Global Initiative for Chronic Obstructive Lung Disease (GOLD). Global Strategy for the Diagnosis, Management, and Prevention of Chronic Obstructive Pulmonary Disease (Update 2015). Available from: http://www. goldcopd.org/ Accessed 20 Jan 2016.
2. Mathers CD, Loncar D. Projections of global mortality and burden of disease from 2002 to 2030. PLoS Med. 2006;3(11):e442

3. Koskela J, Kilpelainen M, Kupiainen H, Mazur W, Sintonen H, Boezen M, Lindqvist A, Postma D, Laitinen T. Co-morbidities are the key nominators of the health related quality of life in mild and moderate COPD. BMC Pulm Med. 2014;14:102.

4. Srivastava K, Thakur D, Sharma S, Punekar YS. Systematic review of humanistic and economic burden of symptomatic chronic obstructive pulmonary disease. PharmacoEconomics. 2015;33(5):467-88.

5. Huber MB, Wacker ME, Vogelmeier CF, Leidl R. Comorbid Influences on generic health-related quality of life in COPD: a systematic review. PLoS One. 2015;10(7):e0132670.

6. Burgel P-R, Escamilla R, Perez T, Carré P, Caillaud D, Chanez P, Pinet C, Jebrak G, Brinchault G, Court-Fortune I, et al. Impact of comorbidities on COPD-specific health-related quality of life. Respir Med. 2013;107(2):233-41.

7. Jones PW. Health status measurement. In: Kolb M, Vogelmeier CF, editors. Outcomes in Clinical Trials. Lausanne: European Respiratory Society; 2013. p. 96-104.

8. Weldam SWM, Schuurmans MJ, Liu R, Lammers J-WJ. Evaluation of quality of life instruments for use in COPD care and research: a systematic review. Int J Nurs Stud. 2013:50(5):688-707.

9. Karch A, Vogelmeier C, Welte T, Bals R, Kauczor HU, Biederer J, Heinrich J, Schulz H, Gläser S, Holle R, et al. The German COPD cohort COSYCONET: aims, methods and descriptive analysis of the study population at baseline. Respir Med. 2016;111:39-46.

10. Jorres RA, Welte T, Bals R, Koch A, Schnoor M, Vogelmeier C. Systemic manifestations and comorbidities in patients with chronic obstructive pulmonary disease (COPD) and their effect on clinical state and course of the disease-an overview of the cohort study COSYCONET. Dtsch Med Wochenschr. 2010;135(10):446-9.

11. Quanjer PH, Stanojevic S, Cole TJ, Baur X, Hall GL, Culver BH, Enright PL, Hankinson JL, Ip MSM, Zheng J, et al. Multi-ethnic reference values for spirometry for the 3-95-yr age range: the global lung function 2012 equations. Eur Respir J. 2012;40(6):1324-43.

12. Celli BR, Cote CG, Marin JM, Casanova C, Montes de Oca M, Mendez RA, Pinto Plata V, Cabral HJ. The Body-Mass Index, Airflow Obstruction, Dyspnea, and Exercise Capacity Index in Chronic Obstructive Pulmonary Disease. N Engl J Med. 2004;350(10):1005-12.

13. American Thoracic Society. ATS statement: guidelines for the six-minute walk test. Am J Respir Crit Care Med. 2002;166(1):111-7.

14. Meguro M, Barley EA, Spencer S, Jones PW. Development and validation of an improved, COPD-specific version of the St. George Respiratory Questionnaire. Chest. 2007;132(2):456-63.

15. Jones PW. Interpreting thresholds for a clinically significant change in health status in asthma and COPD. Eur Respir J. 2002;19(3):398-404.

16. Jones PW, Harding G, Berry P, Wiklund I, Chen WH, Kline Leidy N. Development and first validation of the COPD Assessment Test. Eur Respir J. 2009;34(3):648-54

17. Kon SSC, Canavan JL, Jones SE, Nolan CM, Clark AL, Dickson MJ, Haselden BM, Polkey MI, Man WDC. Minimum clinically important difference for the COPD Assessment Test: a prospective analysis. Lancet Respir Med. 2014;2(3):195-203.

18. Greiner W, Claes C, Busschbach JJ, von der Schulenburg JM. Validating the EQ-5D with time trade off for the German population. Eur J Health Econ. 2005;6(2):124-30.

19. Kim SK, Kim SH, Jo MW, Lee SI. Estimation of minimally important differences in the EQ-5D and SF-6D indices and their utility in stroke. Health Qual Life Outcomes. 2015;13:32.

20. Pickard AS, Neary MP, Cella D. Estimation of minimally important differences in EQ-5D utility and VAS scores in cancer. Health Qual Life Outcomes. 2007:5:70.

21. Zanini A, Aiello M, Adamo D, Casale S, Cherubino F, Della Patrona S, Raimondi E, Zampogna E, Chetta A, Spanevello A. Estimation of minimal clinically important difference in EQ-5D visual analog scale score after pulmonary rehabilitation in subjects with COPD. Respir Care. 2015;60(1):88-95.

22. Putcha N, Puhan MA, Drummond MB, Han MK, Regan EA, Hanania NA, Martinez CH, Foreman M, Bhatt SP, Make B, et al. A simplified score to quantify comorbidity in COPD. PLoS ONE. 2014;9(12):e114438.

23. Grissom RJ, Kim JJ. Effect Sizes for Research: Univariate and Multivariate Applications. New York: Taylor \& Francis Group; 2012.

24. Cox DR SE: Analysis of Binary Data. Monographs on Statistics and Applied Probability 32; Chapmann \& Hall/CRC; 1989. 
25. Gupta N, Pinto LM, Morogan A, Bourbeau J. The COPD assessment test: a systematic review. Eur Respir J. 2014;44(4):873-84.

26. Pickard AS, Yang Y, Lee TA. Comparison of health-related quality of life measures in chronic obstructive pulmonary disease. Health Qual Life Outcomes. 2011;9:26.

27. Jones PW, Brusselle G, Dal Negro RW, Ferrer M, Kardos P, Levy ML, Perez T, Soler-Cataluna JJ, van der Molen T, Adamek L, et al. Health-related quality of life in patients by COPD severity within primary care in Europe. Respir Med. 2011;105(1):57-66.

28. Jones PW, Brusselle G, Dal Negro RW, Ferrer M, Kardos P, Levy ML, Perez T, Soler Cataluna JJ, van der Molen T, Adamek L, et al. Properties of the COPD assessment test in a cross-sectional European study. Eur Respir J. 2011;38(1):29-35.

29. Rutten-van Molken MP, Oostenbrink JB, Tashkin DP, Burkhart D, Monz BU. Does quality of life of COPD patients as measured by the generic EuroQol five-dimension questionnaire differentiate between COPD severity stages? Chest. 2006;130(4):1117-28.

30. van Manen JG, Bindels PJ, Dekker EW, ljzermans CJ, Bottema BJ, van der Zee JS, Schade E. Added value of co-morbidity in predicting health-related quality of life in COPD patients. Respir Med. 2001;95(6):496-504.

31. Sundh J, Johansson G, Larsson K, Linden A, Lofdahl CG, Janson C, Sandstrom T. Comorbidity and health-related quality of life in patients with severe chronic obstructive pulmonary disease attending Swedish secondary care units. Int J Chron Obstruct Pulmon Dis. 2015;10:173-83.

32. Smith MC, Wrobel JP. Epidemiology and clinical impact of major comorbidities in patients with COPD. Int J Chron Obstruct Pulmon Dis. 2014;9:871-88

33. Hong JY, Kim SY, Chung KS, Kim EY, Jung JY, Park MS, Kang YA, Kim SK, Chang J, Kim YS. Factors associated with the quality of life of Korean COPD patients as measured by the EQ-5D. Qual Life Res. 2015;24(10):2549-58.

34. Vanfleteren LE, Spruit MA, Groenen M, Gaffron S, van Empel VP, Bruijnzeel PL, Rutten EP, Op 't Roodt J, Wouters EF, Franssen FM. Clusters of comorbidities based on validated objective measurements and systemic inflammation in patients with chronic obstructive pulmonary disease. Am J Respir Crit Care Med. 2013;187(7):728-35.

35. Sundh J, Stallberg B, Lisspers K, Montgomery SM, Janson C. Co-morbidity, body mass index and quality of life in COPD using the Clinical COPD Questionnaire. COPD. 2011;8(3):173-81.

36. Urff M, van den Berg JW, Uil SM, Chavannes NH, Damoiseaux RA. Depression and heart failure associated with clinical COPD questionnaire outcome in primary care COPD patients: a cross-sectional study. NPJ Prim Care Respir Med. 2014;24:14066.

37. Tsiligianni I, Kocks J, Tzanakis N, Siafakas N, van der Molen T. Factors that influence disease-specific quality of life or health status in patients with COPD: a review and meta-analysis of Pearson correlations. Prim Care Respir J. 2011;20(3):257-68

38. Frei A, Muggensturm P, Putcha N, Siebeling L, Zoller M, Boyd CM, ter Riet G, Puhan MA.. Five comorbidities reflected the health status in patients with chronic obstructive pulmonary disease: the newly developed COMCOLD index. J Clin Epidemiol. 2014;67(8):904-11.

39. Fletcher A, Gore S, Jones D, Fitzpatrick R, Spiegelhalter D, Cox D. Quality of life measures in health care. II: Design, analysis, and interpretation. BMJ. 1992;305(6862):1145-8

40. Xuan J, Kirchdoerfer LJ, Boyer JG, Norwood GJ. Effects of comorbidity on health-related quality-of-life scores: an analysis of clinical trial data. Clin Ther. 1999;21(2):383-403.

41. Hillas G, Perlikos F, Tsiligianni I, Tzanakis N. Managing comorbidities in COPD. Int J Chron Obstruct Pulmon Dis. 2015;10:95-109.

\section{Submit your next manuscript to BioMed Central and we will help you at every step:}

- We accept pre-submission inquiries

- Our selector tool helps you to find the most relevant journal

- We provide round the clock customer support

- Convenient online submission

- Thorough peer review

- Inclusion in PubMed and all major indexing services

- Maximum visibility for your research

Submit your manuscript at www.biomedcentral.com/submit
Biomed Central 